\title{
Creative Education in Japan, Taiwan and Mainland China
}

\author{
Y. Matsuura1, A. Shee' ${ }^{2}$ X. Ding3 \\ ${ }^{1}$ Graduate School of Law, Nagoya University, Nagoya, Japan \\ ${ }^{2}$ College of Law, Chung Cheng University, Chaiyi, Taiwan \\ ${ }^{3}$ College of Law, Renmin University, Beijing, China \\ Email: matuura@law.nagova-u.ac.jp, lawamy@ccu.edu.tw, siangshunf4@163.com
}

Received January 2015

\begin{abstract}
There are three experimental attempts in legal education of East Asia. These experiments promote creative education by introducing a new approach to innovative imagination and creative comparison in a multilingual setting. They use collaborative teaching and new IT tools in the context of "learning by doing."
\end{abstract}

\section{Keywords}

Creative Comparison, Collaborative Teaching, IT Tools, Learning by Doing

\section{Introduction}

Information technology has radically transformed our environment of learning and research. The focus of learning and research has shifted to an environment where participants can acquire skills of independent thinking and creative collaboration. An important element of a new environment is, therefore, how it can assist both teachers and students to expand their innovative imagination and joint work for a better solution.

This paper briefly introduces three attempts to design a new environment for creative education. Then, the paper will discuss a new pedagogy for creative education based upon these three experimental attempts.

\section{Three Experiments}

These experiments are "Cross-border Legal Institution Design” (Nagoya University, Japan), “CCU Global College” (Chung Cheng University, Taiwan) and "Campus Asia” (Renmin University of China and other five universities of China, Japan and Korea) [1].

"Cross-Border Legal Institution Design” is a Ph.D. program to train a group of students from different countries to develop perspectives and skills to transplant a social institution successfully across a national border. It introduced an environment that has five characteristics; (a) multilingualism, (b) group research, (c) project management, (d) mini conference organized by students, and (e) joint publication.

"CCU Global College" is a college program nurturing students to become competent professionals who can work in interdisciplinary teams to tackle global issues. Students are thus encouraged to pick concerned issues on 
their own and join group work to make organized presentations and dialectic discussions.

"Campus Asia" is a student mobility program for globalized world through the network of six universities of China, Japan and Korea. In the first year the program provides introductory courses in law and political science for students of these countries. Language training of Chinese, Japanese and Korean is offered. After a short visit to a partner institution in the first year, students learn one year abroad in the second and third years.

The three experiments attempt to change the mind set of students from seeking the "right answer" in an authoritative source to presenting a result of their independent thinking and discussion. The experiments send participants in a new setting of multi-lingual culture, collaborative work and "learning by doing."

Participants work with their professional peers from other countries. They also work with peers from various disciplines. The environment of conscious diversity inspires more ideas and more options for further reflective discussion. Collaborative research, joint discussion and joint presentation can create occasions [2] for learning by doing without authoritative instructions.

\section{Pedagogical Strategy for Innovative Attempts by Participants}

Three experiments have developed a new environment for creative learning. More design is, however, needed to enhance innovative work by participants. The experiments have developed some pedagogical methods and tools. They are (1) the use of "Mind Map [3]" for more intellectual imagination, (2) creative comparison, (3) collaborative teaching and learning, (4) high-tech environment for learning by doing and (5) tools for comparison.

\subsection{Use of "Mind Map" Approach to Enhance Imagination}

Any thought on a social issue such as same sex marriage begins from identifying relevant problems. Many students find it very hard to find potentially important problems related to the issue. "Mind Map" approach by a student group starts from a key term such as "marriage." All participants contribute their imagination to add terms and notions related to "marriage." One person may suggest "ordinary marriage" and "same sex marriage" to the key term "marriage." Another student may point out "family." After a join work, it happens that student imagination centers on "marriage" but not on "divorce", though the map covers various issues related to same sex marriage. A teacher may suggest the term "divorce" to enhance the collective imagination. A developed "Mind Map" will display one achievement of collaborative thought and create a further occasion of more clarification of an important issue.

\subsection{Creative Comparison}

Comparison often works as a starting point of creative discussion. Participants from different cultures and disciplines produce remarkable examples. For example, "a judge" is an essential figure in law. However, the question of "What is a judge?" produces a variety of responses from different legal cultures. A judge is like an umpire in sports. A judge is like a god-like figure. A judge is like a wise person. A judge is like a dictator. A judge is like a faceless bureaucrat. Presence of radically different views will encourage deeper thought and inspiration.

\subsection{Collaborative Teaching and Learning}

Creative comparison works more effectively when there are two teachers from different countries and a student body with cultural diversity. The teacher may begin a class by saying "Japanese judges are regularly transferred from one court to the other." The teacher explains the reasons for this practice. Then, a whole class is asked, "Are your judges transferred regularly?" Students and teachers can contribute to creative comparison about the regular transfer of judges. The collaborative activity will produce a broader understanding of similarities and differences about a judge.

Given this rich information about a judge, participants can reach a deeper understanding that could be further expanded by their collaboration. Presence of different views is instrumental to deeper analysis and discussion. In addition, diversity of participants makes it possible to access deeper information of law of different countries. Participants themselves turn into knowledge resources about their own society.

\subsection{High-Tech Environment for Learning by Doing}

The study of law used to be a combination of lecturing and note-taking, particularly in East Asia. The innovation 
is essential to creative teaching and learning. High-tech engineering has made it possible to introduce eye contacts and body languages in the classroom and variable forms of communication on the teaching platform [4].

For example, Chung Cheng University introduced TEAL (Technologically Enhanced Active Learning) classroom on campus. With this Chung Cheng University has made significant progress in "Course Websites \& eLectures", "Case Study Drama Classroom" and "Transformation of classroom” [5]. The new classroom makes it possible to videotape student performance, conduct on-line search of information and eLectures.

\subsection{Tools for Comparison}

Often, tools help creative learning. The authors are developing tools that can be used for comparison. The first tool is a multi-lingual terminology of law of China, Japan, Korea and Taiwan. The current terminology under development lists approximately 12,000 terms. Each term is aligned to the terms of equivalent meaning in other jurisdictions. For example, a typical line reads “labor contract”(English), “노동계약”, “勞動契約” (Korea), “労 働契約” (Japan), “勞動契約” (Taiwan)” and “劳动协议” (China). With this tool students can find equivalent notions of other jurisdiction.

Many countries publish their laws in two languages (mostly the native language and English). If laws are displayed in a form of a comparative table, participants can understand laws of East Asia through English translation. This is a project of Bilingual KWIC. Given the multi-lingual terminology mentioned above, participants will have easy access to the statutory information of East Asia.

Authors are promoting a project called "LawPack [6]." In order to understand the current law, lawyers use various sources of information such as legislative history, current laws, judicial interpretations, court decisions, academic writings and empirical findings. A LawPack is an information package on a particular topic of law for each jurisdiction. Creative comparison needs easy access to deeper information about law of each country.

It is obvious that creative education calls for more tools of this sort.

\section{Conclusions}

This paper suggests that creative education demands radical re-design of an environment for learning and research. It argues that conscious design and strategy are essential to collaborative work under "learning by doing" approach.

Though the authors emphasized the significance of high-tech environment, they are aware of the danger of high-tech classroom. Professor Abdul Paliwala rightly pointed out, "Technology will not in itself create good ideas. Good ideas come from intellectual imagination in an era of the new orthodoxy of independent, active, reflective learning" [7].

This paper emphasizes the significance of cross-boundary and inter-disciplinary network of professionals and the people for more imaginative and creative education in higher learning.

\section{Acknowledgements}

This technology was developed by Nagoya University and used for the Japanese Law Translation website of the Japanese Government. http://www.japaneselawtranslation.go.jp/kwic/?re=02http://jalii.law.nagoya-u.ac.jp/project/enbkportal

\section{References}

[1] For Details of These Experiments, See the Web Site of Each Program. http://www.law.nagoya-u.ac.jp/ leading/en/index-e.html http://www.law.ruc.edu.cn/eng/sep/?unit=Campus\%20Asia http://oia.ccu.edu.tw/www/college_ii.html?nID=6

[2] Peters, P. (2007) Gaining Compliance through Non-Verbal Communication. Pepperdine Dispute Resolution Law Journal, 7, 87-112. https://www.lexisnexis.com/ap/auth/

[3] Busan, T. (1996) The Mind Map Book, Plume.

[4] Peters, P. (2007) Gaining Compliance through Non-Verbal Communication. Pepperdine Dispute Resolution Law Journal, 7, 87-112. https://www.lexisnexis.com/ap/auth/

[5] Shee, A. (2013) In Search of a Modern Confucius for Effective Teaching in Law: A Trial Project to Promote Interac- 
tive Learning in Taiwan. Taiwan University Law Review, 18, 299-328. http://www.law.ntu.edu.tw/ntulawreview/8/02/822.html

[6] http://www.lawpack.taiwanlii.ccu.edu.tw/lawpack/

[7] Paliwala, A. (2008) Three Dimensions of E-Learning: From Resource-Based to Transactional: From E to M. CCU Law Review, 24, 55-76. 